\title{
Secondary revascularization - repeated percutaneous coronary intervention or coronary artery bypass graft?
}

\author{
Tomislav Šipić*, Krešimir Štambuk, Davor Richter, Hrvoje Stipić, Igor Šesto, \\ Janko Nossan-Szavits, Robert Bernat \\ Clinic for Cardiovascular Disease Magdalena, Krapinske Toplice, Croatia
}

67-year old female patient with previous history of hypertension, hyperlipoproteinemia and coronary artery disease was admitted to our hospital for recoronarography. 6 months ago she had a $\mathrm{PCl}$ procedure on the right coronary artery (RCA) and the $\mathrm{ACx} . \mathrm{PCl}$ on the RCA was performed successfully with two BM stent. During the procedure on the LCA the guiding catheter made a dissection of the LMCA and the ascending aorta producing a crescent-shaped shadow. The dissection was successfully solved percutaneously, with implantation of multiple BM stents in LAD, avoiding the surgical intervention at that moment. The crescent-shaped shadow in ascending aorta disappeared as well. Systolic function was preserved.

She is presenting now with dyspnea and stable angina, and the angio is to be done for reevaluation of the disease. On the recoronarography, the finding was the diffuse in-stent restenosis in LAD with good collaterals from the RCA. The stents implanted in the RCA were good, and the ACx was patent, with a stenosis. An ischemic cardiomiopathy has developed, with EF of $30 \%$. Clinical question was whether there was a viable myocardium in LAD perfusion territory demanding secondary revascularization. In order to find viable myocardium, its amount and localization, the stress MRI was performed.

Viability study showed that the biggest amount of viable myocardium was in LAD perfusion territory, making reason- able the secondary revascularization. Two possibilities were confronting - bypass grafting or reintervention with $\mathrm{DE}$ stents. The decision was made and successful reintervention with DE stents was performed during hospitalization. Before discharge, stress test was negative (96\%), and on the control, three months later, echo showed improved EF LV of $45 \%$, and stress test was negative as well (110\%).

The necessity for secondary revascularization is our every day problem. There are many issues that have to be taken in consideration when deciding of secondary revascularization. This case showed the proposed strategy for solving some dilemmas and finding the best solution.

KEYWORDS: coronary artery disease, in-stent restenosis, revascularisation.

\section{Received: $5^{\text {th }}$ Mar 2013}

*Address for correspondence: Magdalena - klinika za kardiovaskularne bolesti, Ljudevita Gaja 2, HR-49217 Krapinske Toplice, Croatia.

Phone: +385-49-244-444

E-mail: tomisipi@inet.hr

\section{Literature}

1. Cutlip DE, Chauhan MS, Baim DS, Ho KK, Popma JJ, Carrozza JP, et al. Clinical restenosis after coronary stenting: perspectives from multicenter clinical trials. J Am Coll Cardiol. 2002;40(12):2082-9.

2. Kim RJ, Wu E, Rafael A, Chen EL, Parker MA, Simonetti O, et al. The use of contrast-enhanced magnetic resonance imaging to identify reversible myocardial dysfunction. N Engl J Med. 2000;343(20):1445-53.

3. Dangas GD, Claessen BE, Caixeta A, Sanidas EA, Mintz GS, Mehran R. In-stent restenosis in the drug-eluting stent era. J Am Coll Cardiol. 2010;56(23):1897-907. 